\title{
研究速報
}

\section{係数シフトバイラテラルフィルタによるラビリンス風画像の 生成}

\section{Generation of Labyrinthine Picture-like Images by Weight-Shifted Bilateral Filter}

\author{
正会員平岡透门，浦 浜 喜 一十†
}

Toru Hiraoka $^{\dagger}$ and Kiichi Urahama ${ }^{\dagger \dagger}$

\begin{abstract}
In this letter, we propose a non-photorealistic rendering method for generating labyrinthine picturelike images from photographs. Our proposed method utilizes a modified bilateral filter (BF) called the weight-shifted $\mathrm{BF}$. We validate the effectiveness of the proposed method by conducting experiments using the image of Lenna and other example images.
\end{abstract}

キーワード：ノンフォトリアリスティックレンダリング, バイラテラルフィルタ, 係数シフト, ラビリンス風画像

\section{1. ま え がき}

ラビリンス風画像を生成するノンフォトリアリスティッ クレンダリング $(\mathrm{NPR})$ 法 ${ }^{12)}$ が提案されている. ラビリ ンス風画像とは，迷路のように入り組んだ線をほぼ等間隔 に敷き詰めたような画像である.Pedersen らは微分方程式 による方法 ${ }^{1)}$ を, Sparavignaらはタイリングによる方法 ${ }^{2)}$ を提案している.これらの方法は, 処理手順が複雑で計算 の手間が多い.

そこで本稿では, 従来法と似た直線的な模様のラビリン 又風画像を生成する簡単な NPR 法を提案する。簡単なラ ビリンス風画像を生成する NPR 法として非等方フィルタ を用いる方法 ${ }^{3) 4}$ が提案されているが，これらの方法で生 成されるラビリンス模様は文献 1)2) で得られる直線的なも のではなく曲線的なものであり，またラビリンス模様の間 隔が広い. 提案法は，バイラテラルフィルタ ${ }^{5)}$ の係数を変 えたフィルタ（以下，係数シフトバイラテラルフィルタ）の 反復計算を用いる。提案法の有効性を検証するために，レ ナの画像（図 1 参照）を用いた実験を行い，生成されるラ

2012 年 11 月 5 日受付, 2012 年 12 月 18 日再受付, 2012 年 12 月 26 日 採録

†大分工業高等専門学校 情報工学科

(厂 870-0152 大分市大字牧 1666 番地, TEL 097-552-7548) ††九州大学 大学院芸術工学研究院 コミュニケーションデザイン科学部門 ( ₹ 815-8540 福岡市南区塩原 4-9-1, TEL 092-553-4510)

$\dagger$ Department of Computer and Control Engineering, Oita National College of Technology

(1666, Maki, Oita-shi, 870-0152, Japan)

$\dagger \dagger$ Department of Communication Design Science, Faculty of Design, Kyushu Uniersity

(4-9-1, Shiobaru, Minami-ku, Fukuoka-shi 815-8540, Japan)

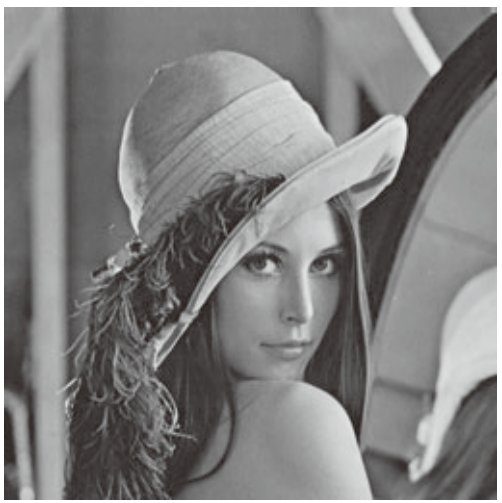

図 1 レナの画像 Image of Lenna.

ビリンス模様を確認する。 また，レナの画像以外のいくつ かの画像にも提案法を適用して，生成されるラビリンス風 画像の見栄えを確認する。ラビリンス風画像の見栄えの評 価は，直線的なラビリンス模様が生成され，ラビリンス模 様の間隔が狭いものであれば，良好とする。

\section{2. 方 法}

提案法は，大きく二つの処理で実行される。一つ目の処 理は, 原画像に係数シフトバイラテラルフィルタを複数回 かけて，ラビリンス模様を生成するというものである。二 つ目の処理は，一つ目の処理で得られた画像（以下，処理 1 後の画像) のラビリンス模様として残さない画素を，閾 值処理で原画像の画素值に置き換えることによって，最終 的なラビリンス風画像を作成する. 


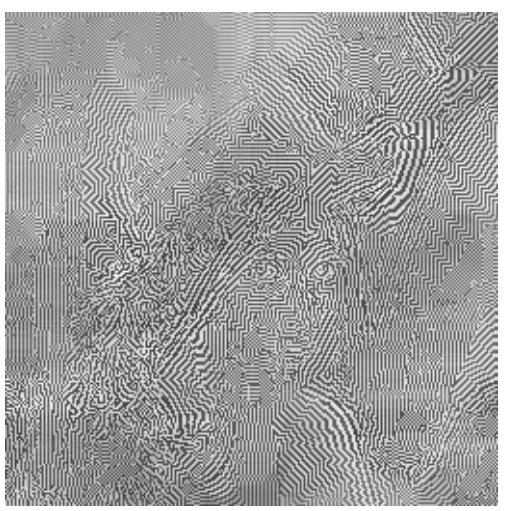

図 2 処理 1 後の画像 $(\alpha=10.0, \beta=0.001, w=10$, $S=50$ )

Image after processing $1(\alpha=10.0, \beta=0.001, w=10$, $S=50)$.

\section{1 係数シフトバイラテラルフィルタ} 空間座標 $(i, j)$ での入力画素值を $d_{i, j}^{(0)} \in[0,255]$ とし， 係数シフトバイラテラルフィルタでの出力画素值 $d_{i, j}^{(t)} \in$ $[0,255] （(t)$ は反復回数）を式 $(1)$ で計算する.

$$
\begin{aligned}
d_{i, j}^{(t)}=\frac{\sum_{k=i-w}^{i+w} \sum_{l=j-w}^{j+w} e^{-\alpha D_{i, j, k, l}-\beta I_{i, j, k, l}^{(t-1)}} d_{k, l}^{(t-1)}}{\sum_{k=i-w}^{i+w} \sum_{l=j-w}^{j+w} e^{-\alpha D_{i, j, k, l}-\beta I_{i, j, k, l}^{(t-1)}}} \\
D_{i, j, k, l}=(i-k)^{2}+(j-l)^{2} \\
I_{i, j, k, l}^{(t-1)}=\left(255-\left|d_{i, j}^{(t-1)}-d_{k, l}^{(t-1)}\right|\right)^{2}
\end{aligned}
$$

ここで， $\alpha$ と $\beta$ は正定数， $w$ はウィンドウサイズである. $\alpha$ は座標 $(i, j)$ からの距離の影響を調節するパラメータで あり， $\alpha$ の值が大きいほど座標 $(i, j)$ から離れている画素 ( $D_{i, j, k, l}$ の值が大きい画素) の影響を受けにくくなる. $\beta$ は座標 $(i, j)$ の画素值 $d_{i, j}^{(t)}$ との差の絶対值の影響を調整す るパラメータであり， $\beta$ の值が大きいほど画素值 $d_{i, j}^{(t)}$ との 差の絶対值の小さい画素 $\left(I_{i, j, k, l}^{(t-1)}\right.$ の值が大きい画素) の影 響を受けにくくなる。ラビリンス風画像では，ラビリンス 模様の間隔を狭く表現した方が良いため， $\alpha$ の值は大きく， $\beta$ の值は小さく設定する． $w$ の值は $\alpha$ の值が小さいほど小 さくすることができ，計算処理を高速化することができる. 式 (1) の係数シフトバイラテラルフィルタを $S$ (正整数) 回かけることで，ラビリンス模様が生成される。

\section{2 閾值処理}

処理 1 後の画像の画素值の出現頻度のヒストグラム（濃 度ヒストグラム）には，明確な二つの山と一つの谷が存在 する．濃度ヒストグラムの谷の画素值を閾值 $T$ (正整数) として，閾值以下の画素值は処理 1 後の画像の画素值に, 閾值より大きい画素值は係数シフトバイラテラルフィルタ をかける前の原画像の画素值にすることで，最終的なラビ リンス風画像が生成される。閾值 $T$ は画像ごとに処理 1 の 結果において最適と考えられる值が設定される.

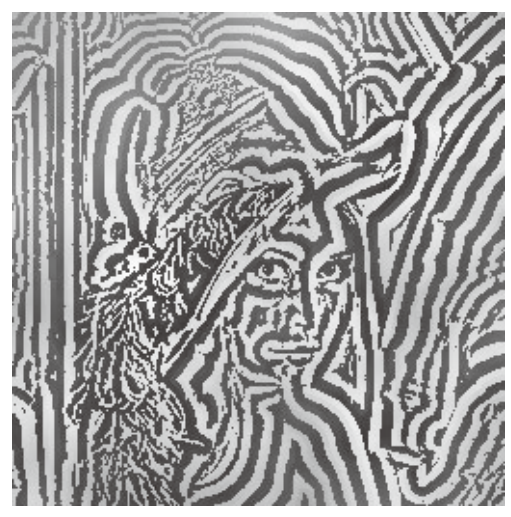

図 3 処理 1 後の画像 $(\alpha=1.0, \beta=0.001, w=10$, $S=50)$

Image after processing $1(\alpha=1.0, \beta=0.001, w=10$, $S=50)$.

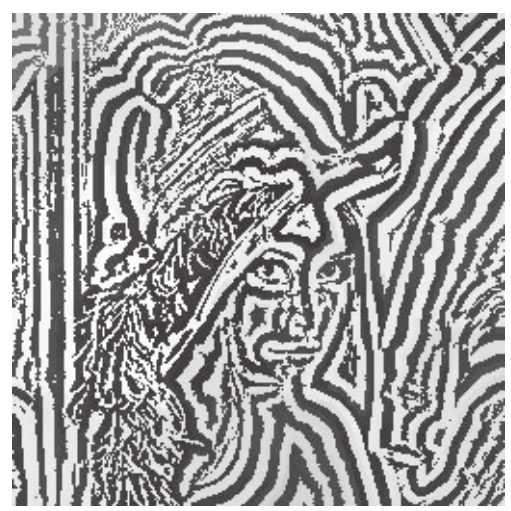

図 4 処理 1 後の画像 $(\alpha=10.0, \beta=0.01, w=10$ $S=50)$

Image after processing $1(\alpha=10.0, \beta=0.01, w=10$, $S=50)$.

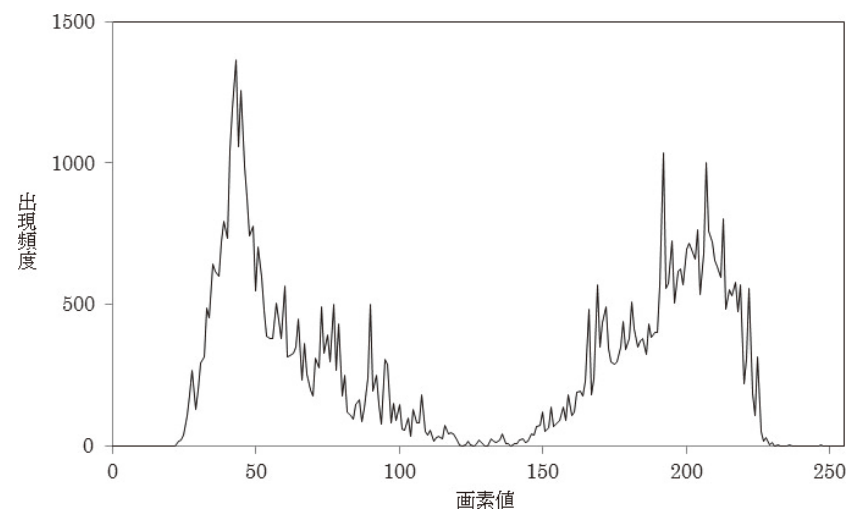

図 5 濃度ヒストグラム Density histogram.

\section{3. 実 験}

まず，256×256pixel のサイズのレナの画像を用いた実 験を行った. ここで，係数シフトバイラテラルフィルタの各 種パラメータを $\alpha=10.0, \beta=0.001, w=10, S=50$ と 設定した. $\alpha=10.0$ と設定した理由は，ラビリンス模様の間 隔を狭くするためである. $\alpha=10.0$ と $\alpha=1.0$ ( $\beta=0.001$, $w=10, S=50)$ として, 処理 1 後の画像をそれぞれ図 2 と図 3 に示す。図 2 は図 3 よりもラビリンス模様の間隔が 


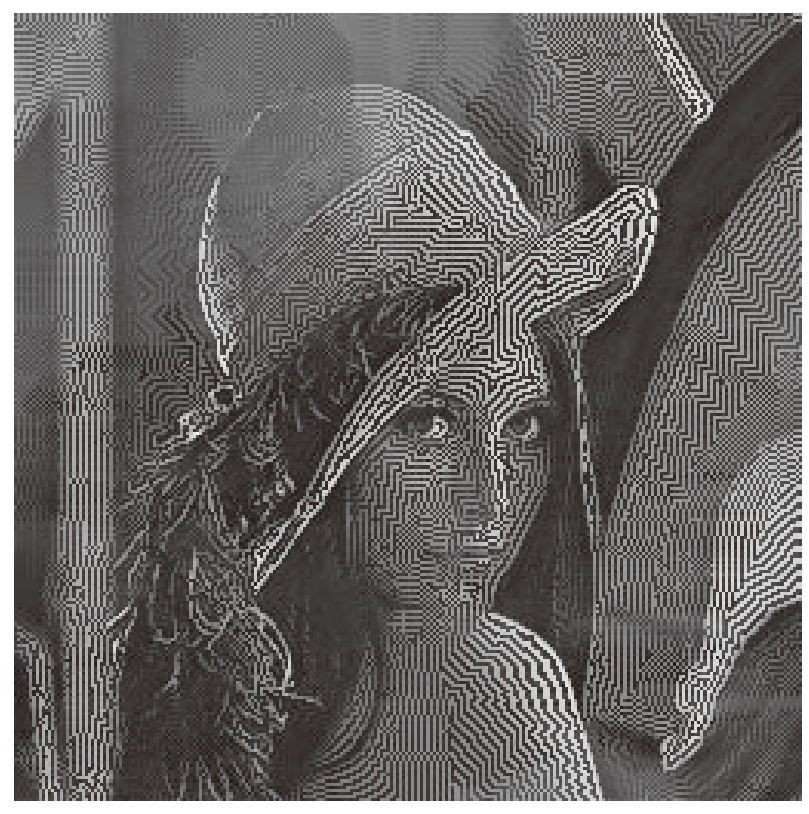

図 6 ラビリンス風画像

Labyrinthine picture like image.
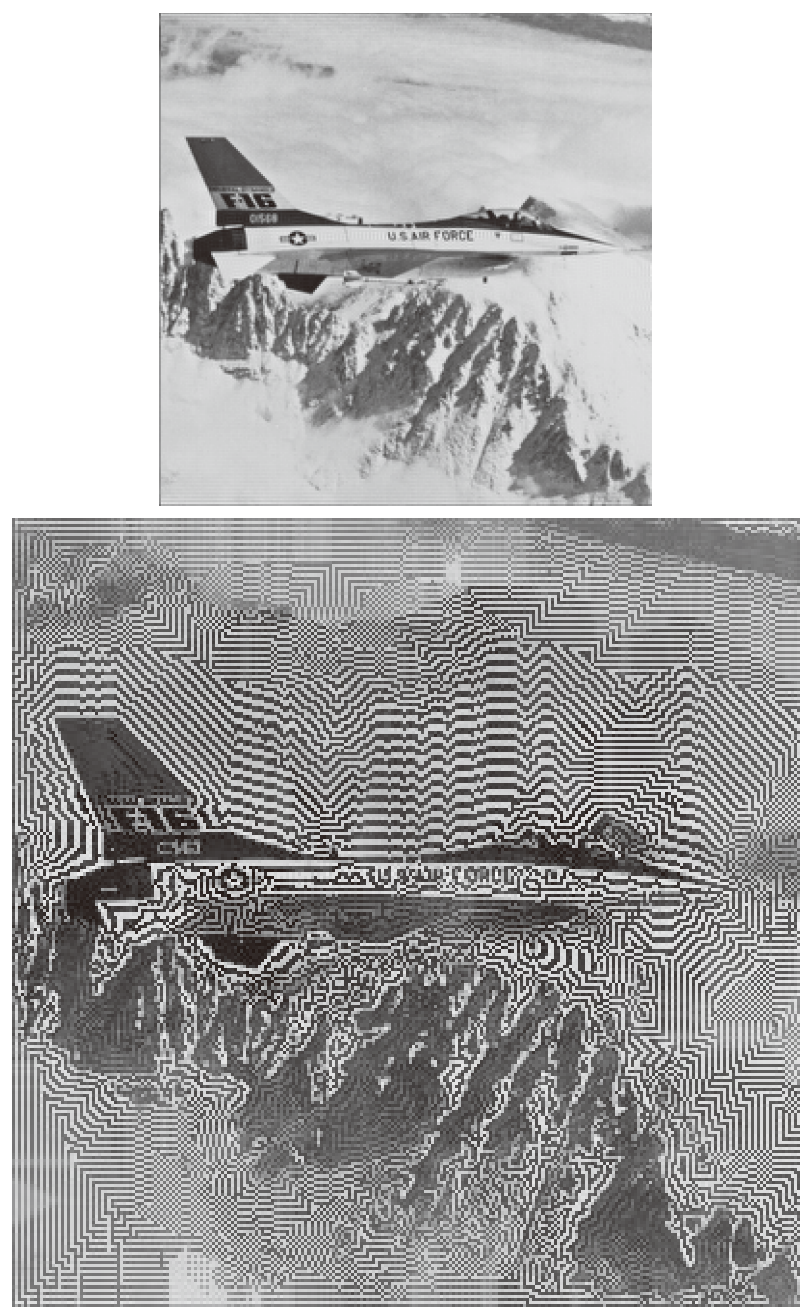

図 7 ラビリンス風画像 (Airplane)

Labyrinthine picture like image (Airplane).

狭いことがわかる． $\beta=0.001$ と設定した理由は，ラビリン ス模様の間隔を狭くするためである. $\beta=0.01(\alpha=10.0$, $w=10, S=50)$ として, 処理 1 後の画像を図 4 に示す.
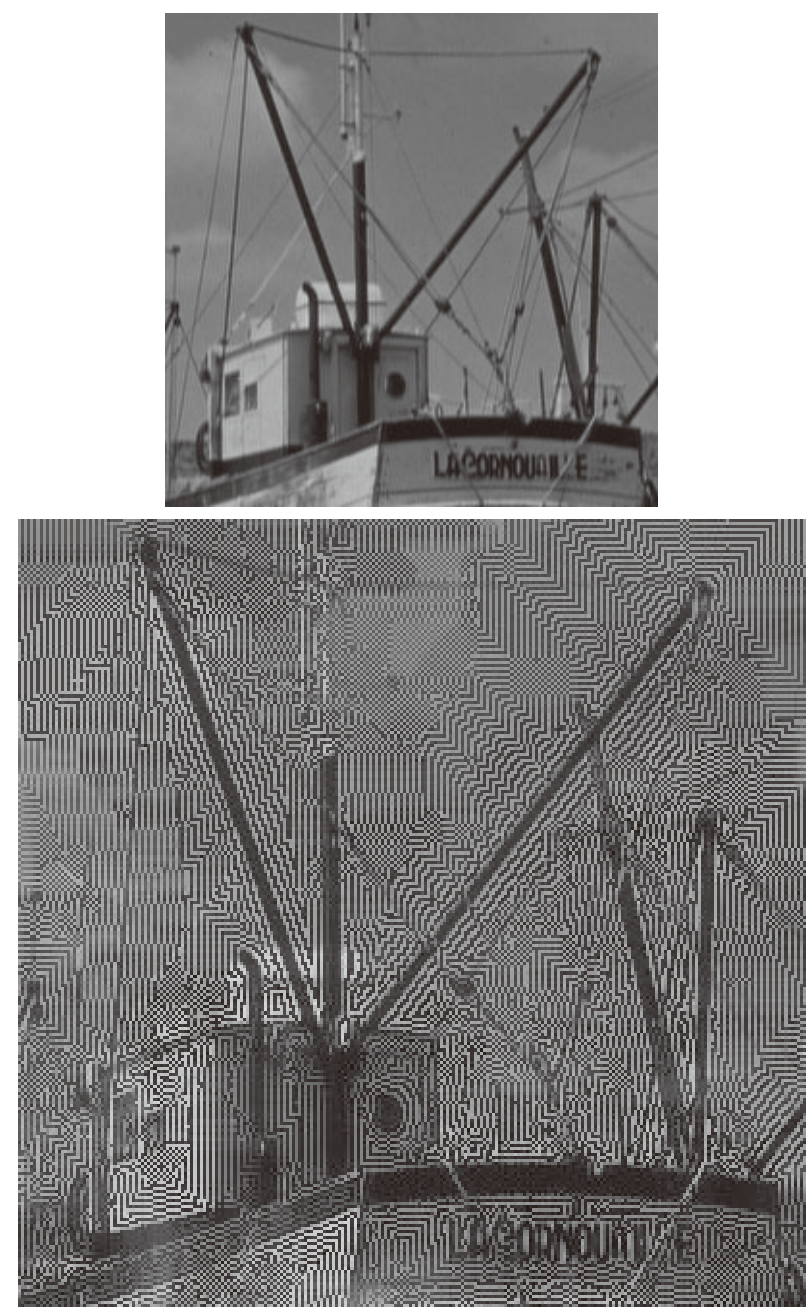

図 8 ラビリンス風画像 (Boat)

Labyrinthine picture like image (Boat).

図 2 は図 4 よりもラビリンス模様の間隔が狭いことがわか る. $w=10$ と設定した理由は， $\alpha=10.0$ と設定すれば隣 接画素以外の影響はほとんど受けなくなるため, $w=1$ と 設定すれば良いが，図 3 の $\alpha=1.0$ と設定した場合も考慮 して余裕を持ってここでは $w=10$ とした. $S=50$ と設定 した理由は，実験に抒いて 50 回の反復計算で画像の変化 がほとんどなくなったためである。

係数シフトバイラテラルフィルタをかけた処理 1 後の画 像を図 2 に, 処理 1 後の画像の濃度ヒストグラムを図 5 に 示す．図 5 より，閾值 $T$ を二つの山の間の谷の画素值 130 とした。最終的に生成されたラビリンス風画像を図 6 に示 す. 図 6 より，ラビリンス模様が明瞭に表れており，比較 的綺麗なラビリンス風画像が生成されていることがわかる. 次に, レナの画像以外の 3 枚の画像 $(256 \times 256$ pixel $)$ に提案法を適用した。このとき， $\alpha=10.0, \beta=0.001$, $w=10, S=50$ として, 閾值 $T$ はそれぞれの処理 1 後 の画像の濃度ヒストグラムの谷の画素値とした。実験の結 果を図 7 から図 9 に示す. 図 7 から図 9 の上の画像が原画 像，下の画像がラビリンス風画像である。図 7 から図 9 よ り, どのラビリンス風画像にもラビリンス模様が明膫に表 

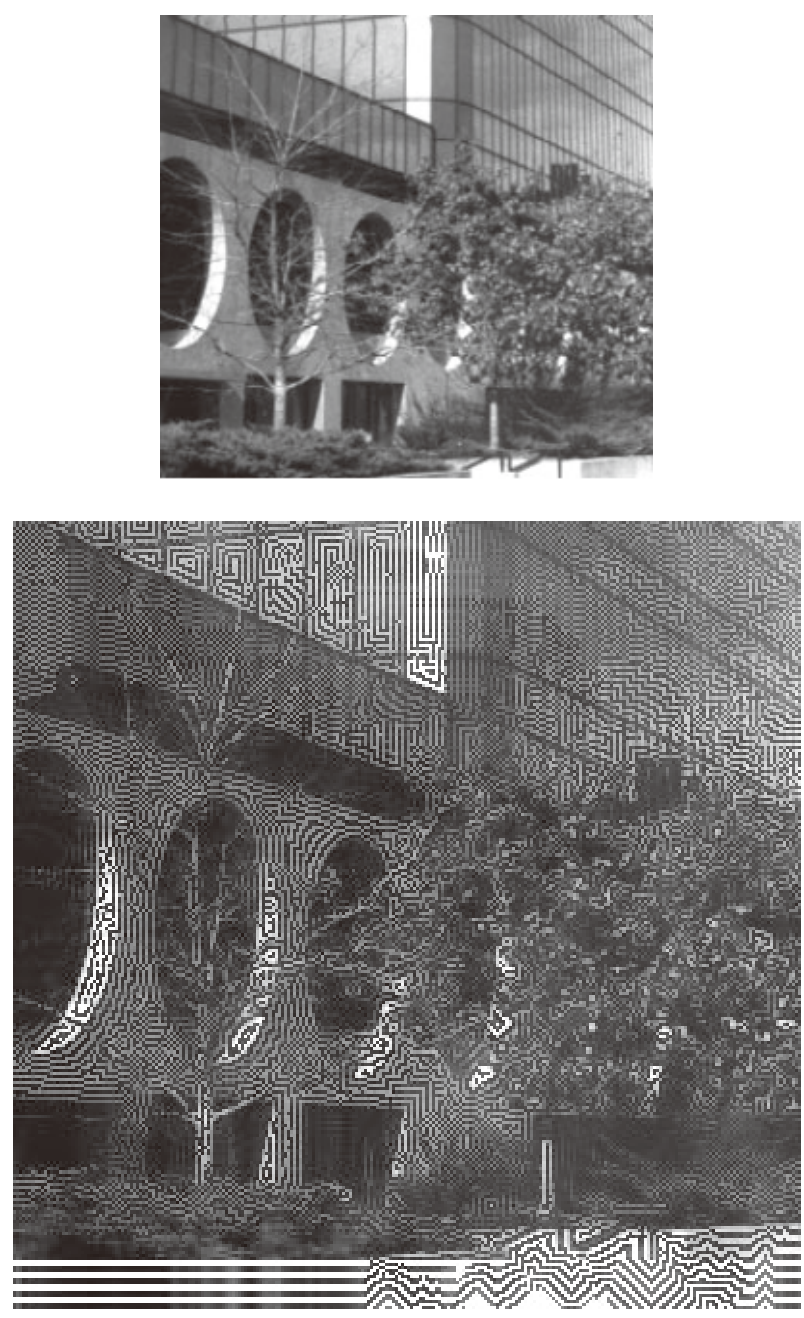

図 9 ラビリンス風画像 (Building)

Labyrinthine picture like image (Building).

れていることがわかる.バイラテラルフィルタを使用して いるので，原画像において画素值があまり変化のない領域 では，ラビリンス模様の間隔が若干大きくなってしまうこ とが確認できる。

\section{4. むす び}

係数シフトバイラテラルフィルタを用いて，写真画像か らラビリンス風画像を生成する簡単な方法を提案した。提 案法を用いることで，良好なラビリンス風画像を生成でき ることがわかった。しかし，提案法よりも文献 1)2）の方 法で得られたラビリンス風画像の方がラビリンス模様が規 則正しく生成されている。今後の課題は，より多くの画像 に適用して，より綺麗なラビリンス風画像を生成できるよ うに提案法を改良することである。また，原画像の画素值 の変化が小さい領域のラビリンス模様の間隔を小さくする ようにすることも今後の課題である. さらに，提案法をカ ラー画像に適用することも今後の課題である.

\section{〔文献〕}

1) H. Pedersen and K. Singh: "Organic Labyrinths and Mazes,", NPAR'6, pp.76-86 (2006)

2) A. Sparavigna and B. Montrucchio: "Non-photorealistic Image
Rendering with a Labyrinthine Tiling,", CoRR, abs/cs/0609084 (2006)

3）常セン，井上光平，浦浜喜一: “非等方ショックフィルタによる迷路風ス クラッチ画の生成”, 映情学誌, 61, 10, pp.1463-1466 (2007)

4) 胡忠英, 浦浜喜一: “バイラテラル距離に基づく非等方 TSP アート”, 信学論, J94-D, 4, pp.746-749 (2011)

5) C. Tomasi and R. Manduchi: "Bilateral Filtering for Gray and Color Images,", Proc. ICCV, pp.839-846 (1998)

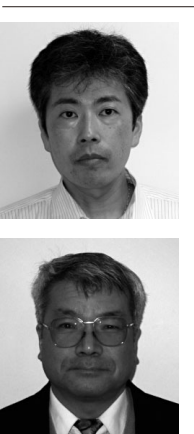

平势岡透 1995 年，九州芸術工科大学芸術工学 部画像設計学科卒業. 1997 年, 同大学大学院芸術工学研 究科博士前期課程修了. 2005 年, 同大学大学院芸術工学 研究科博士後期課程修了．現在，大分工業高等専門学校 情報工学科准教授. 博士 (工学) . 地理情報処理，画像 処理，地域防災に関する研究に従事. 正会員.

浦浜 喜いち 1980 年, 九州大学大学院工学研究科 博士後期課程修了.同年，同大学助手. 1989 年，九州工 業大学助教授. 現在, 九州大学大学院芸術工学研究院教 授. 工学博士. パターン認識, 画像処理, ノンフォトリ アリステイックレンダリングに関する研究に従事. 